\title{
Retinopathy of prematurity: incidence report of outliers based on international screening guidelines
}

\author{
Juan Carlos Romo-Aguas' ${ }^{1}$ Ana González-H.León', Miroslava Paolah Meraz-Gutiérrez \\ and María A. Martínez-Castellanos ${ }^{1,2^{*}}$
}

\begin{abstract}
Aim: The objective of this study is to report the incidence of retinopathy of prematurity (ROP) outliers that fall outside the screening guidelines of the American Academy of Ophthalmology (AAO) in our country.

Methods: A retrospective review of 503 records of newborns evaluated in our institution between January 2011 and March 2017. We analyzed the data by subgroups based on gestational age (GA), birth weight (BW) and stage, focusing on the outliers that don't meet the criteria of the screening $A A O$ guidelines ( $G A \leq 30$ weeks, $B W \leq 1500 \mathrm{~g}$ ).

Results: Of the 503 records, 352 had some degree of ROP, $91.76 \%$ being bilateral, and $26.2 \%$ require treatment. The mean GA at delivery was $30.56 \pm 2.33$ weeks, and the mean BW was $1287.90 \pm 338.52 \mathrm{~g}$. For the current AAO/AAP ROP screening, $19.9 \%$ were outliers, of which (57\%) had ROP diagnosis and (38\%) required treatment.
\end{abstract}

Conclusions: ROP diagnosis in newborns of BW $>1500 \mathrm{~g}$ or GA>30 weeks is not uncommon in Mexico, and it is important to take this into account to adjust the selection criteria on each population to reach all the infants at risk.

Keywords: Retinopathy of prematurity, Epidemiology blindness, Neonatal intensive care unit

\section{Background}

Retinopathy of prematurity (ROP) is a potentially blinding condition characterized by abnormal vascular growth of the immature retina that affects preterm infants [1]. Each year about 15 million babies are born prematurely [2]. Developing countries are now seeing a spike due to the higher premature birth rates, decreased access to neonatal resources, and possibly due to lack of awareness or training of healthcare professionals; in Latin America is the leading avoidable cause of childhood blindness [3].

The latest ROP screening guidelines published by the American Academy of Pediatrics and the American Academy of Ophthalmology (AAO/AAP), recommend that all infants with gestational age $(\mathrm{GA})$ of $\leq 30$ weeks

\footnotetext{
*Correspondence: mamc@dr.com

2 Retina Service, Asociación para Evitar la Ceguera Hospital "Luis Sánchez Bulnes" I.A.P., Vicente Garcia Torres No. 46 Coyoacán, 04030 Mexico, D.F.,

Mexico

Full list of author information is available at the end of the article
}

and/or $\leq 1500 \mathrm{~g}$ of birth weight (BW), or with unstable clinical course should be screened [4].

In our country, the Mexican Secretary of Health (SSASpanish acronym) made an update in ROP screening guidelines in July 2015, increasing the threshold in order to screen all newborns that were born $\leq 34$ weeks at BW or/and $\leq 1750 \mathrm{~g}$ of BW [5]. The study of Flores-Santos in 2007 and 2 report prevalence series in Mexico are the basis of this adjustment [6-8], in which they found patients that had ROP and require treatment that fell outside the AAO/AAP guidelines.

The purpose of this study is to report the incidence of ROP in infants who do not fall within the AAP/AAO screening criteria in our center, to help identify infants at risk for ROP in Mexico and other middle-income countries. 


\section{Methods}

A retrospective review of all the records of ROP screening program in our institution, which englobe 503 infants who underwent evaluation at the Asociación para Evitar la Ceguera en México, "Dr. Luis Sánchez Bulnes" I.A.P. between January 2011 and March 2017. The patients are referred to us from inside Mexico City, and other regions of the country (southeast and central more frequently); and this is because some of the states don't have a proper screening program (personel or training) that could reach all pre-term infants.

A considerable percentage of these patients arrive at end-stages of the disease because based on the newborns health they are brought on incubators, only if the are clinically stable to be transported on an ambulance; or sometimes after they are discharged, and by that time it could be already too late for timely diagnosis and treatment. It is important to know that not all patients who arrive at the hospital are referred with a diagnosis of ROP, but are sent due to risk factors.

At our hospital triage, every infant with a history of pre-term birth, low birth weight or any perinatal complications is sent to the pediatric retina department, where a trained retina specialist team do a complete ophthalmologic examination (this evaluation is performed by two pediatric retina specialist MAMC or LCE and retina fellows tutored by them); including all the past medical history (gestational age, birth weight at delivery, demographic information, medical history, previous interventions, other systemic associations, and prior treatment).

After this evaluation is done, we use a registration format (see Additional file 1) where we include all relevant medical history and the ophthalmologic findings including ROP status; according to the International Classification of ROP (ICROP) [9], with the maximum grade of retinopathy defined as the highest stage and lowest zone on each eye.

Also as part of our follow-up procedures, we take 5 protocol pictures (one centered on the optic nerve, superior, inferior, nasal and temporal) every visit to compare one and other, with The RetCam II (Clarity Medical Systems, Pleasanton, Calif) (see Fig. 1) and recently we also use ultra wide field fundus camera Optos Daytona ${ }^{\circledR}$ (Optos, Dunfermline, United Kingdom).

When non-surgical treatment is needed, we use antiangiogenic therapy with either intravitreal injection of Bevacizumab or Ranibizumab. Our threshold for antiangiogenic treatment is based on the AAP/AAO 2018 recommendations [4], Zone I, any stage with plus disease; Zone I Stage 3 without plus disease; Zone II Stage 2 or 3 with plus disease. We also include Zone II Stage 3 without plus disease.
When no treatment is required, the infant is monitored closely until complete vascularization of the retina is achieved. For cases of ROP that do not regress or are too advanced for antiangiogenic treatment, laser therapy or vitrectomy is performed. Indications for treatment followed the guidelines from The Early Treatment for Retinopathy Of Prematurity (ETROP) study [10].

Patients were grouped according to GA, BW, and stage of ROP for analysis. The study mainly focused on infants that were outliers to the AAO/AAP screening guidelines ( $\mathrm{GA} \leq 30$ weeks and $\mathrm{BW} \leq 1500$ grams) in which a diagnosis of ROP was made.

\section{Results}

We report all the ROP screening records from our hospital from January 2011 to March 2017, with a total of 503 infants. The distribution was very similar in both genders, being 259 (51.5\%) females and 244 (48.5\%) males. The mean GA at delivery was $30.56 \pm 2.33$ weeks (23-37 weeks) and the mean BW was $1287.90 \pm 338.52 \mathrm{~g}$ (540 and $2932 \mathrm{~g}$ ).

Throughout this period, $70 \%$ of the screenings were detected with some degree of ROP on either eye, which represents 352 of 503 newborns; $91.76 \%$ being bilateral (323/352). In Tables 1 and 2, we present the distribution of this population, dividing them into groups based on BW and GA at birth (see Fig. 2).

The distribution based on the ROP stage at the time of evaluation was: 94 infants were on stage 1 (18.7\%), 117 on stage $2(23.3 \%), 77$ on stage $3(15.3 \%), 44$ on stage 4 (8.8\%), 32 on stage $5(6.4 \%)$; and 132 infants $(26.2 \%)$ required and received treatment.

For our data analysis, we realized Kolmogorov-Smirnov test to determine if the distribution of the variables GA and BW was normal, which both result $<0.000$. Also, we calculate the area under de curve for these two variables for GA was 0.337 , and for BW 0.369 .

In order to find outliers, we group the populations that meet each of the guidelines. For the current AAO/AAP ROP screening, 100 infants (19.9\%) would be considered outliers, of which 57 (57\%) had ROP diagnosis and $15(38 \%)$ required treatment. And for the SSA guidelines employed in our country, only 6 patients $(1.2 \%)$ would be left out as outliers; and only 2 (33.3\%) had ROP diagnosis and non of them require treatment (see Fig. 3).

\section{Discussion}

We reviewed 503 charts of infants screened for ROP diagnosis from January 2011 to March 2017. The main purpose of the study was to determine how many infants would be left out if we would base our screening program only in AAO/AAP guidelines [4]. The source to 


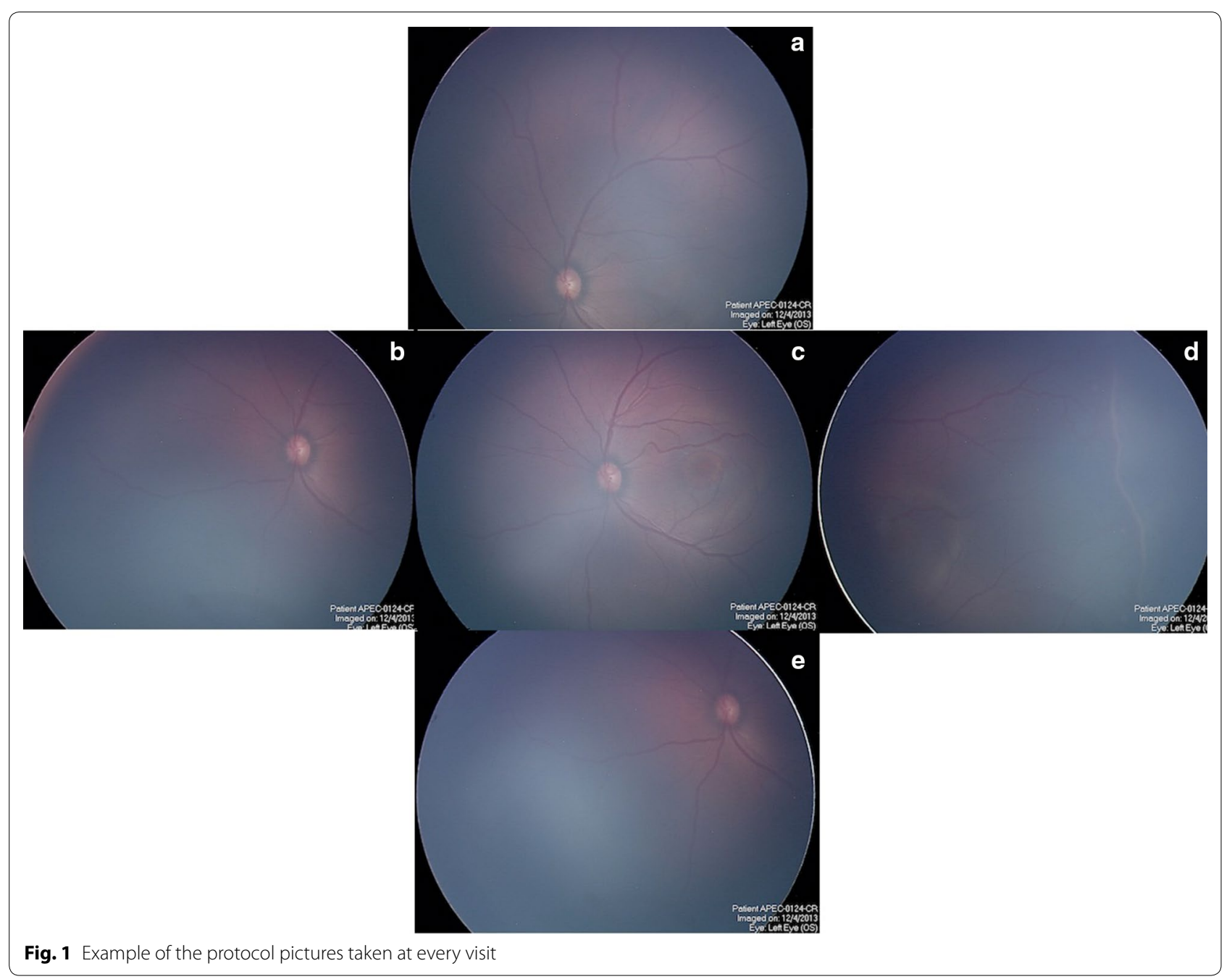

Table 1 Demographic data presenting gestational age in relation to ROP diagnosis

\begin{tabular}{|c|c|c|c|c|c|c|}
\hline \multirow{4}{*}{$\begin{array}{l}\text { Stage } \\
\text { ROP diagnosis: }\end{array}$} & \multicolumn{6}{|c|}{ Gestational age (weeks) } \\
\hline & \multicolumn{2}{|l|}{$\leq 30$} & \multicolumn{2}{|c|}{$30.1-33.6$} & \multicolumn{2}{|l|}{$\geq 34$} \\
\hline & \multicolumn{2}{|l|}{219} & \multicolumn{2}{|l|}{131} & \multicolumn{2}{|l|}{24} \\
\hline & Treated & Non-treated & Treated & Non-treated & Treated & Non-treated \\
\hline 1 & 5 & 43 & 2 & 35 & 0 & 9 \\
\hline 2 & 12 & 62 & 3 & 35 & 0 & 5 \\
\hline 3 & 53 & 0 & 20 & 1 & 3 & 0 \\
\hline 4 & 18 & 5 & 4 & 9 & 3 & 2 \\
\hline 5 & 5 & 12 & 11 & 2 & 0 & 2 \\
\hline Total & 93 & 122 & 49 & 82 & 6 & 18 \\
\hline
\end{tabular}

determine the threshold of these guidelines comes from industrialized countries but, previews series in Mexico from 2006 to $2008[6,7,11]$ report ROP patients in newborns $>32$ weeks and GA of 2000 g. For this reason the SSA in 2015 increase the threshold to 34 weeks of GA and $1750 \mathrm{~g} \mathrm{BW}$. 
Table 2 Demographic data presenting birth weight in relation to ROP diagnosis

\begin{tabular}{|c|c|c|c|c|c|c|}
\hline \multirow{4}{*}{$\begin{array}{l}\text { Stage } \\
\text { ROP diagnosis: }\end{array}$} & \multicolumn{6}{|c|}{ Birth weight (g) } \\
\hline & \multicolumn{2}{|l|}{$\leq 1500$} & \multicolumn{2}{|c|}{ 1501-1999 } & \multicolumn{2}{|l|}{$\geq 2000$} \\
\hline & \multicolumn{2}{|l|}{306} & \multicolumn{2}{|l|}{60} & \multicolumn{2}{|l|}{8} \\
\hline & Treated & Non-treated & Treated & Non-treated & Treated & Non-treated \\
\hline 1 & 8 & 66 & 0 & 21 & 0 & 2 \\
\hline 2 & 14 & 92 & 1 & 11 & 0 & 1 \\
\hline 3 & 64 & 0 & 11 & 1 & 2 & 0 \\
\hline 4 & 20 & 15 & 5 & 6 & 0 & 1 \\
\hline 5 & 7 & 20 & 0 & 4 & 0 & 2 \\
\hline Total & 113 & 193 & 17 & 43 & 2 & 6 \\
\hline
\end{tabular}

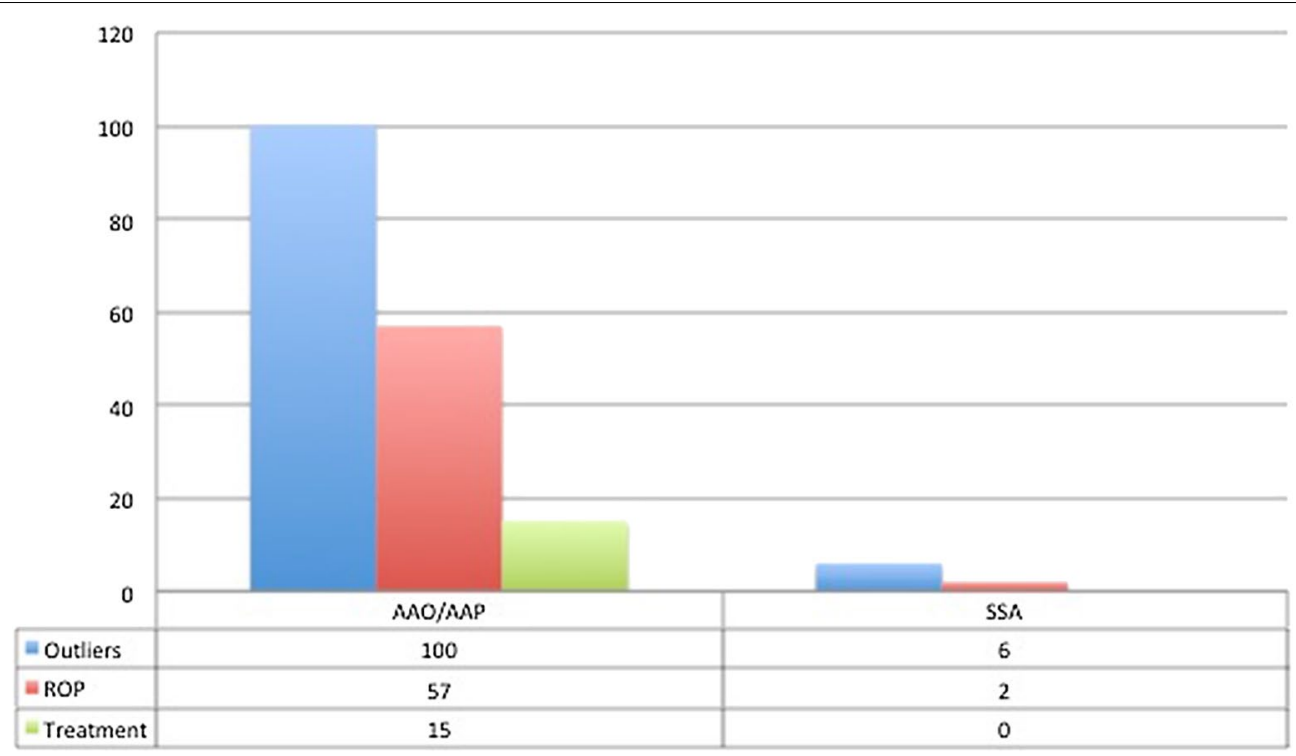

Fig. 2 Graph displaying the number of outliers based on the different ROP screening guidelines

The screening criteria used in developed nations may no be applicable for middle-income countries. For example, Gilbert et al. show that if the United Kingdom 2008 screening criteria were applied, an overall of $13 \%$ of newborns in middles- and low-income countries would not be examined $(<32$ weeks or $<1500 \mathrm{~g})$ [12]. Zimmermann et al. presented the prevalence of ROP in Latin America throughout 2000-2010, ranging from 6.6 to $82 \%$ at any stage and of severe ROP from 1.2 to $25 \%$ based on AAO/AAP guidelines [13]. Also in Freitas et al., recently reported that in a series of 10 years only reported $8 / 602$ patients with $>32$ weeks or $>1500 \mathrm{~g}$ [14]. In other middleincome countries, like India, a report showed that the incidence of infants $>1500 \mathrm{~g}$ treated for threshold ROP with cryotherapy was $15.3 \%$ [15]. And in Lithuania, 54\% of the infants needing treatment for ROP were $>1500 \mathrm{~g}$ at birth [16].

We found that $19.9 \%$ of the screened newborns fell out of the AAO/AAP 2018 guidelines, 57\% of these outliers had some degree of ROP, and 38\% required treatment. Compared to the SSA guidelines were only $1.2 \%$ are outliers, and only $2(33 \%)$ patients had ROP. None of them required treatment. One of the factors associated could be that in neonatal care units with lower survival rates in middle or low-income countries, our selection criteria for screening should be expanded [17].

Whatever the reason for this variability, the difference of outliers between the two guidelines is striking, and it is important to take this into account to adjust the selection criteria on each population. Within the 


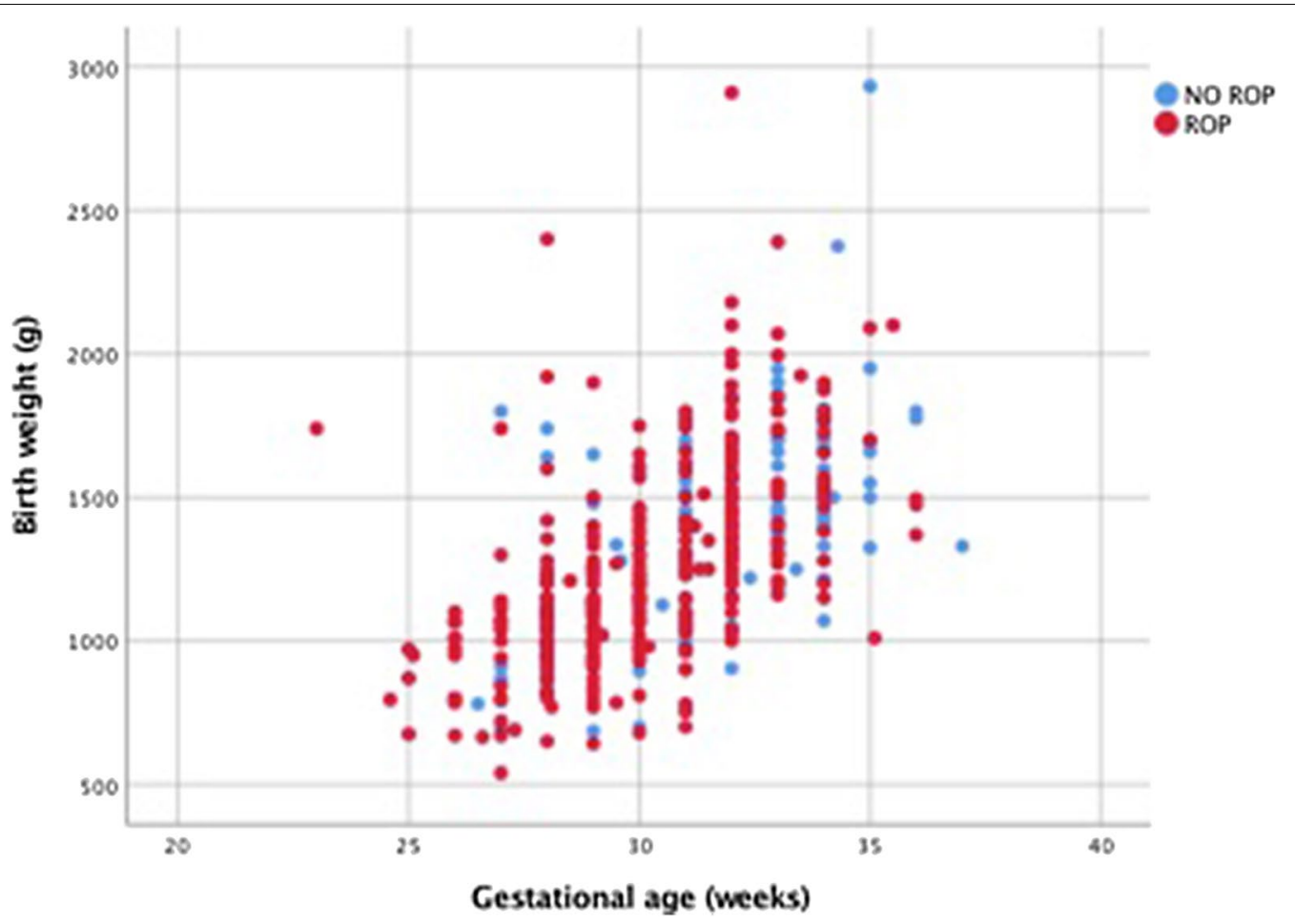

Fig. 3 Birth weight and gestational age distribution based on ROP diagnosis

limitations of the study, we have the retrospective nature and the selection bias. As a tertiary health care center, the majority of our patients referred for ROP screening require treatment, probably because stage 1 or 2 are followed up in second-level hospitals.

\section{Conclusions}

In conclusion, ROP diagnosis in newborns of $\mathrm{BW}>1500 \mathrm{~g}$ or $\mathrm{GA}>30$ weeks is not uncommon in Mexico and other developing countries. Based on our population, applying the SSA guidelines established in our country in 2015 only $1.2 \%$ of the patients would be left out, compared to $57 \%$ with AAO/AAP guidelines. And modification of the current screening guidelines in other middle-income countries could be useful to include infants at risk.

\section{Supplementary information}

Supplementary information accompanies this paper at https://doi. org/10.1186/s40942-019-0203-x.

Additional file 1. The format presented as additional material was made by the personnel at our hospital in the admission and follow-ups of every infant that undergoes ROP screening. It contains the following sections: patient ID number, BW, GA, risk factors, a diagram based on ICROP classification, and finally diagnosis/treatment section.

\section{Abbreviations}

ROP: retinopathy of prematurity; AAO/AAP: American Academy of Pediatrics and the American Academy of Ophthalmology; GA: gestational age; BW: birth weight; SSA: Mexican Health Secretary (Spanish acronym); ICROP: International Classification of Retinopathy of Prematurity; ETROP: the early treatment for retinopathy of prematurity.

\section{Acknowledgements \\ None.}

\section{About this supplement}

This article has been published as part of International Journal of Retina and Vitreous, Volume 5 Supplement 1, 2019: Wide-field imaging in retina and vitreous diseases. The full contents of the supplement are available at https://journ alretinavitreous.biomedcentral.com/articles/supplements/volume-5-suppl ement-1.

\section{Authors' contributions}

Conception and design: MAM and JCR; Data collection MAM, AGH, JCR, MPM; Writing the article: JCR, MPM, AGH; Critical revision of the article: MAM, JCR, AGH, MPM. All authors read and approved the final manuscript.

\section{Funding}

The publication costs for this paper in the supplement were made possible with unconditional financial support from Optos. The sponsor had no input into the content of articles, which were independently prepared by the authors and have undergone the journal's standard peer-review process.

\section{Availability of data and materials}

The database used during the current study is available from the corresponding author on reasonable request.

\section{Ethics approval and consent to participate}

The study was approved by the ethics committee of "Asociación Para Evitar la Ceguera en México I.A.P." and conducted accordingly to the Declaration 
of Helsinki. No consent was required because it is a retrospective study that consisted of file review.

\section{Consent for publication}

Not applicable.

\section{Competing interests}

The authors declare that they have no competing interests.

\section{Author details}

${ }^{1}$ Retina Department, Asociación para Evitar la Ceguera en México I.A.P, Mexico City, Mexico. ${ }^{2}$ Retina Service, Asociación para Evitar la Ceguera Hospital "Luis Sánchez Bulnes" I.A.P., Vicente Garcia Torres No. 46 Coyoacán, 04030 Mexico, D.F., Mexico.

Published: 12 December 2019

\section{References}

1. Gilbert C, Foster A. Childhood blindness in the context of VISION 2020The Right to Sight. Bull World Health Organ. 2001;79:227-32.

2. World Health Organization. Preterm birth. 2015. http://www.who.int/ mediacentre/factsheets/fs363/en/. Accessed 10 Aug 2019.

3. Arnesen L, Durán P, Silva J, Brumana L. A multi-country, cross-sectional observational study of retinopathy of prematurity in Latin America and the Caribbean TT-Estudio de observación, multinacional y transversal de la retinopatía del prematuro en América Latina y el Caribe. Rev Panam Salud Publica. 2016;39:322-9.

4. Fierson WM, American academy of pediatrics, American academy of ophthalmology american academy of orthoptists, et al. Screening examination of premature infants for retinopathy of prematurity. Pediatrics. 2018;142.

5. Instituto Mexicano del Seguro Social. Detección, Diagnóstico y Tratamiento de Retinopatía del Prematuro en el Segundo y Tercer Nivel de Atención. 2015

6. Flores-Santos R, Hernandez-Cabrera MA, Henandez-Herrera RJ, Sepulveda-Canamar F. Screening for retinopathy of prematurity: results of a 7-year study of underweight newborns. Arch Med Res. 2007;38:440-3. https://doi.org/10.1016/j.arcmed.2006.12.002.
7. Ramírez-ortíz MA, Villa-guillén M, Villanueva-garcía D, et al. Screening criteria for retinal examination of Mexican premature newborns at risk of developing. Bol Med Hosp Infant Mex. 2008;65:179-85.

8. González-Urquidi O, Fuente-Torres M. Incidencia de retinopatía del prematuro en el hospital Dr. Manuel Gea González. Rev Mex Oftalmol. 2004;78:1-4.

9. Article S. The international classification of retinopathy of prematurity revisited. Arch Ophthalmol. 2005;123:991. https://doi.org/10.1001/archo pht.123.7.991.

10. Good WV. Final results of the early treatment for retinopathy of prematurity (ETROP) randomized trial. Trans Am Ophthalmol Soc. 2004;102:1684-94.

11. García H, González-cabello H, Soriano-beltrán CA, et al. Frequency and severity of retinopathy of prematurity in a neonatal intensive care unit. Gac Med Mex. 2018;154:475-81.

12. Gilbert C. Retinopathy of prematurity: a global perspective of the epidemics, population of babies at risk and implications for control. Early Hum Dev. 2008;84:77-82. https://doi.org/10.1016/j.earlhumdev .2007.11.009.

13. Zimmermann J, Tartarella MB, Zin A, et al. Prevalence of retinopathy of prematurity in Latin America. Clin Ophthalmol. 2011;5:1687-95.

14. Freitas AM, Mörschbächer R, Thorell MR, Rhoden EL. Incidence and risk factors for retinopathy of prematurity: a retrospective cohort study. Int $J$ Retina Vitr. 2018;4:1-8. https://doi.org/10.1186/s40942-018-0125-z.

15. Dogra MR, Narang S, Biswas C, Gupta A, Narang A. Threshold retinopathy of prematurity: ocular changes and sequelae following cryotherapy. Indian J Ophthalmol. 2001:49:97-101.

16. Sharief $L$, Lightman $S$, Blum-Hareuveni $T$, et al. Clinical outcome of retinal vasculitis and predictors for prognosis of ischemic retinal vasculitis. Am J Ophthalmol. 2017;177:206-12. https://doi.org/10.1016/j.ajo.2017.02.028.

17. Zin AA, Elisabeth $M$, Moreira $L$, et al. Retinopathy of prematurity in 7 neonatal units in Rio de Janeiro: screening criteria and workload implications. Pediatrics. 2015;126:e410-7. https://doi.org/10.1542/peds.2010-0090.

\section{Publisher's Note}

Springer Nature remains neutral with regard to jurisdictional claims in published maps and institutional affiliations.
Ready to submit your research? Choose BMC and benefit from:

- fast, convenient online submission

- thorough peer review by experienced researchers in your field

- rapid publication on acceptance

- support for research data, including large and complex data types

- gold Open Access which fosters wider collaboration and increased citations

- maximum visibility for your research: over $100 \mathrm{M}$ website views per year

At BMC, research is always in progress.

Learn more biomedcentral.com/submissions 